\title{
The DIY Phd Student Doctoral Education and Punking the Podcast
}

\author{
Tara Brabazon ${ }^{1}$ \\ ${ }^{1}$ Dean of Graduate Research, Professor of Cultural Studies, Flinders University, Australia \\ Correspondence: Tara Brabazon, Flinders University, Australia. \\ Email: tara.brabazon@flinders.edu.au
}

Received: April 10, 2019

Accepted: May 23, 2019

Online Published: June 1, 2019

doi: 10.23918/ijsses.v5i4p22

\begin{abstract}
Sound has a potent role in the history of teaching and learning, yet sonic andragogy remains uneven, marginalized and undertheorized. A key media intervention is revisioning this historiography and enlivening sonic educational studies. This article summons the distinctiveness of podcasting, alongside its renewed popularity, with specific attention to the innovations in mode, genre, delivery mechanism, audience and community building capacities when deployed in higher degree programmes. While the PhD differs widely in its international formulation, particularly with regard to the role of coursework, publications and duration of the degree, the national specificities can travel and be shared through sonic deterritorialized media. This article 'punks' the podcast, showing how PhD students can transform the shape of their candidature through sound.
\end{abstract}

Keywords: Doctor of Philosophy, Podcasting, DIY Media, Maker Culture, Punk Learning, Digital Media, Social Media

\section{Introduction}

I have held a clustered series of professorial appointments: Media, Communication, Creative Media, Education and Cultural Studies. Through the transformations to the political economy, media industries and creative industries, it has been a remarkable and confronting time to teach, research, consult and examine within these disciplines. The transformations of and from social media have been intricate, unexpected and surprising. Indeed the phrase 'social media' has reached a point of saturation where its usefulness must now be questioned. It is over-stuffed with promise, hyperbole, marketing and innovation. The diversity of genres, modes and communication systems within this category means that without precise understandings of - and literacies in - Instagram, Twitter, LinkedIn, Snapchat and Facebook, then flaws, mis-steps and errors in the creation and promulgation of content will emerge.

This is a screen age, and an age of screens. Yet it has a soundtrack of surprises. Podcasting has been the awkward stepchild sitting in the corner of social media. Encasing a small, internationally dispersed group of ardent and committed producers and audiences, it was a capsuled community. The proliferation of podcasts emerged through the repurposing and time-shifting of content. News programmes started to slice content and disseminate microinfo through podcasts. But the moment where podcasting solidly grafted to popular culture emerged in 2016 with Serial. A weekly podcast with a true crime inflection, the makers of This American Life released a 'who done it' style of programming. It gained traction, momentum and a huge international audience. The episodes, listened to in order, were 
popular, dominating the iTunes podcasting chart, and were also critically successful, winning a Peabody Award in April 2015 for its innovation in form and genre. It holds the world record for podcast downloads. The innovations were clear and continued and transformed many of the $19^{\text {th }}$ century storytelling strategies. For example, Charles Dickens published Great Expectations in serial form before the self-standing novel (Sanford, 2002). Such strategies create innovative responses from readerships and build loyalty to and via narrative, whether through fiction or non-fiction. Serial captured all the profound advantages of podcasting. While the regular, weekly delivery of podcasts built an audience (Dasal, 2018), the capacity existed for new listeners to discover the programmes at any point. At the moment of personal discovery, the entire series can be downloaded and listened to in a new time and context. This is a profound advantage of disintermediated and deterritorialized media. The intrigue, mystery and fear that encircles serial killers was potently conveyed through a sound-only platform. This mode of programming arched back to an earlier history of radio and radio plays. Mashing together news, entertainment news, thrillers and crime documentaries, Serial moved podcasting and non-fiction into new spaces. It also created the awareness, consciousness and literacy about podcasts, from the technical details - how to download episodes - through to listening to and engaging with sound-only narrative and content. In a screen-based aged, the capacity to enjoy content with the eyes at rest is an important intervention in popular culture, and literacy history and theory.

Sonic social media is special and distinctive. Sound has a history and historiography, and podcasting occupies an important chapter and moment in this narrative and analysis. This article takes that distinctiveness, alongside its renewed popularity, to understand a definitive slice of podcasting that has been a minoritarian but present part of its history. Academic podcasts are probed and discussed, with specific attention to the innovations in mode, genre, delivery mechanism, audience and community building capacities, when they are deployed in higher degree programmes. While the PhD differs widely in its international formulation, particularly with regard to the role of coursework, publications and duration of the degree, the national specificities can travel and be shared through sonic deterritorialized media.

The work punk is used with intent in this article. I am not summoning the tired visage of John Lydon or the thrashing guitars of The Clash. While there has been some engagement with 'Punk Learning," which is defined as "memorable, self-regulated, completely controlled by the student and real" (Coles, 2014: 7 ), that is not the project of this article. Doctoral education cannot be self-regulated. It must work at the edge of knowledge, grasping and clawing at the filaments of what we know, to take one conceptual, theoretical or empirical leap beyond the acceptable, the cited and the referenced. Punk activates a desire to transcend, to reflect on and challenge the normative, and to offer defiant ways of thinking and being. It is also transitory. Inevitably the edgy is looped into the commonsensical cloth. John Lydon recorded butter advertisements. The Clash has an array of 'Best of' collections. But for this moment in doctoral education - for this moment in the history of podcasting - it is necessary to pause and recognize the passionately provocative dialogues, hybridities and innovations emerging in this space of combination. Indeed, the second half of this article features an array of examples and emerging genres that operate between podcasting and the PhD. Put another way, and citing Aimee Knight's provocative question, "there are sundry forms of seeing and being seen. Are there as many ways to hear and be heard?" (Knight, 2019) 
The answer to her question is a productive and profound yes. The podcast is a closed listening system, cocooned in headphones and occupying odd and liminal spaces: commuter trains, cars, on exercise equipment or walking. Podcasts are as mobile as a mobile phone (Laurin, 2018). The affordances of mobile computing and mobile platforms means that there has been, to cite Camille Baker, "increased amateur creativity, as well as changing how audiences engage with these practices" (Baker, 2019, p. 4). The enclosed and solitary listening experience renders it distinct and different from the communal listening to music in a club or pub, further shared through corporeal commitments like dancing. Podcasting - as sonic social media - is sharing in a way that is distinct to the engagements with popular music. The audience - the listener - is integral to the experience and the diverse nodes, modes and places for that listening create an array of transitory, ephemeral connections between space and sound (Eiman, 2017). Specifically therefore, this article uses practice-led research methods, crafting knowledge through the production of sonic artefacts (Maalsen, 2019). The examples serve to model and cascade new sonic genres, new knowledge dissemination tactics, and opportunities for connectivity and community. But further, the focus on doctoral education is distinctive. Podcasts have been used for over a decade in undergraduate education. Their effectiveness in enabling undergraduate student learning is ambivalent at best. Used to timeshift lectures, the resultant decline in attendance and subsequent avoidance of the content through the delayed sonic delivery, has not been successful. It may be transformative in the future, but the genre of the undergraduate lecture is not well packaged or configured through podcasting. Further, because of the lack of thought in this specific production of sonic artefacts, an array of other proxies for learning, such as critical thinking, have not been revealed. The task of this article is to take the audiences for podcasting seriously, and focus on research dissemination, rather than teaching.

My positioning is important for the argument expressed - and the trajectory of - this article. I am currently a dean of graduate research in an Australian university, but also one of the earliest podcasters. As a professor of media, communication and creative media in Canada and the United Kingdom, I taught podcasting. I have taught with podcasts for over a decade. I have researched and published on podcasting. For me, podcasts configure a powerful platform integral to my public intellectual role (Goodall, 2010). They allow a subtle and considered movement between the diverse roles of a scholar: researcher, teacher, community developer and participant, administrator, manager, leader and citizens (Kim, 2019). My last three academic positions have been leadership roles, so I have used my media expertise to enable the careers of others, and podcasts have been crucial to building a community (Foley, 2018) of students and scholars, and creating awareness of key issues, theories and concepts.

Each of these priorities or functions could provide the impetus for this research. Instead, this article on podcasting emerged from an unusual source. I interviewed Dr Philippa Grand, Commissioning Editor at Emerald Publishing in Bingley Yorkshire, as part of my vlog series for Flinders University, in Adelaide Australia (Brabazon \& Grand, 2018). It was a rare and productive conversation, as an academic commissioning editor made herself available to discuss the present and future of publishing. While I was discussing the proliferation and diversity of publishing through ebooks and audio books, Dr Grand expressed her enthusiasm for podcasting and how they develop an author platform for academics. My face captured surprise. Podcasting was always the unpopular runt of the social media litter. It had its fans and long term practitioners and supporters. It is a solid community. But in the last five years, 
podcasting is no longer the Cinderella of social media. But - when considering the trajectory of that particular fairy tale - perhaps the metaphor is increasingly accurate. It is definitively part of popular culture, and enables the success of other media platforms. While Serial's success could not be predicted, there were trajectories for this boost in popularity. When Professor Steve Redhead and I recorded a podcast titled 'The University of Trumpland' just after Donald Trump's inauguration as President of the United States, thousands of downloads followed (Brabazon \& Redhead, 2016). We realized that there was a key and important clustering of arguments to explore. Therefore Trump Studies: An intellectual guide to why citizens vote against their own interests followed the argument and shape of this podcast (Brabazon, Redhead, \& Chivaura, 2018). We deployed 'sonic persuasion' (Goodall, 2011) to granularize and texture our analysis.

As I travelled on the train back to Manchester Airport after my interview with Philippa Grand in Bingley, Yorkshire, I appreciated that podcasting was a cultural lever for academics, building connections, communities and alliances. When Steve Redhead died, I received thousands of tweets, emails, cards, letters and notes, including people who had worked with him for decades, former students, DJs, journalists, editors and readers of his books. But the people who were most upset by his death were those who listened to our podcasts for a decade (Brabazon, 2018). It is remarkable that a well know academic, and a 66 year old man, had his most passionate fans through podcasting.

There is a point to be made through these stories. Podcasting matters. The rationale for this 'mattering' is nested in wider configurations of sonic media. Visual media platforms are - literally - in the face of the viewer. Sonic media texts can be downloaded and nest - nestle - into the life of the listener. They are heard while commuting, walking or exercising. Sonic media are important because they accompany other activities. They fit into the life of the listener. Referred to as a secondary, supplementary or attendant platform, they have a convenience not provided by video, which requires full attention. While Nii-Daako Darko may have been optimistic, the maxim is an interesting one: "video is king right now, but audio and podcasts are the future" (2018, p. 49).

This nestling effect is important for scholars and academic writers trying to disseminate their research. Podcasts are an intimate medium, whispering into someone's ear, sharing content in a way that fits into the life, timetable and patterns of the listener. Because of its asynchronous nature, it is not imposed on the life of others. It weaves around the responsibilities of life like a vine. It can also offer a distinctive voice, place and positioning. This can be important for women in particular. Podcasting can enable, naturalize and solidify the place of women in academic life, granting a voice, views and space through patriarchal priorities in research and teaching policies (Tiffe \& Hoffman, 2017, p. 115-118).

Connections and communities are created through sound. Sound summons and creates different modes of relationships and allegiances. Yet how this impact and engagement is measured remains complex. Apple released their Podcast Analytics in 2017 (Quah, 2018), and the Corporation has revealed that not only are podcasts part of popular culture, but the people that listen to podcasts are what Miranda Katz described as advertisers' "holy grail" (Katz, 2018), hyper-engaged and supportive audiences. They stay throughout the show, no matter the length. Podcast listeners do not want standardization, but expect experimentation in form and length. This is a large audience. Podcast subscriptions on iTunes have 
expanded beyond 1 billion, with the number of unique monthly podcast listeners recorded at 75 million. While podcasting is part of narrowcasting and disseminating highly specialist content, it is clearly - now - a component of popular culture.

Podcasts settle into the context and environment of the listener (Kane, 2015, p. 2-21). Video demands attention, and we live in an attention-poor age. Also, podcasts are simpler to make than vlogs or videocasts. Making high quality audio is cheaper and easier. When talking with people in an interview format, the camera intimidates. With an audio recorder on a desk, academics often gather higher quality content. Video also demands more of presenters. If multiple takes are required, then they are inefficient with regards to time. There is more dexterity with editing audio. Errors can be corrected at speed and ease.

Podcasts are audio content. But they are much more. They are a special form of sonic media, providing audio files in a series. They can be downloaded - pulled - directly to the listener. They are also available by subscription - syndication - where content is pushed to listeners when it is released. Podcasts are bespoke and customized content. There are millions of podcasts and unlike radio, it features a long tail and remarkable diversity. Academics can locate and build a deterritorialized audience, and a larger one than is possible in most national scholarly settings.

The word podcast is a portmanteau of ipod and broadcast. Podcasts were and are a disruptive media. When Apple added them to iTunes in 2005, they were naturalized in the suite of sound and vision. It was also recognized by scholars at this time that podcasting holds an important role in teaching and learning (Campbell, 2005, p. 32-47). Their success and proliferation have disconnected many audiences from radio and created profound time-shifting options for audio content. It is an individual and individuated medium where very small topics can find a large international audience. This means that academics working in very specialist areas can gain a trans-local scholarly audience. This strategy is particularly effective when triangulating other social media platforms to create awareness of the content, including Facebook, Twitter, LinkedIn, Instagram and Pinterest.

A key question when considering the popularity of platforms, particularly lagged after their invention and emergence is: what changed? After customized, specialist attention and commitment, and through the sonic-literacy building potential of Serial, what changed to diversify and proliferate the podcast? One clear answer is technology-driven. High quality domestic hardware, software and applications, intuitive in their interfaces, are available to create podcasts. The mobile phone is also important to this story. From the arrival of the smart phone, simple applications for 'voice memo' recording were available. These sonic resources and applications have increased in number and scale. While using the phone as a recorder may seem convenient, better options are available in the long-term. The Zoom microphones offer an array of powerful and appropriate options, moving from the Zoom 2 through to the Zoom 6. Using conventional batteries and an SD card, this is an effective, convenient and mobile platform for academics. For editing, Accoustica's Mixcraft is strong. It is an intuitive interface, and it of the appropriate size and complexity for a podcast, with a voice as the dominant recorded object. Mixcraft maintains a library of open access sound loops that can be used for sonic branding of introductions and conclusions. A researcher, a project, an institute, a centre or an organization can gain 
a continuity of sonic identity and audience and brand loyalty through such strategies. Similarly, podcast hosting has many options, but there is a frontrunner through scope, scale and longevity: Liberated Syndication (www.libsyn.com). Files can be loaded up to Libsyn, and then released from the podcatcher to populate iTunes. Codes for embedding content in websites and learning management systems are also available.

With a Zoom recorder, editing software, podcatcher and pop screen, a researcher, and particularly a PhD student, can create and disseminate content. This is a DIY culture. These sonic materials can be created at home or in a work office with few resources and no specialist attention from university marketers. The researcher is not reliant on any other part of the university, or any other service, to disseminate academic content. Further, through academic repositories, podcasts can now - with an attendant abstract - incorporate audio series (Spinelli, 2019). Therefore the second half of this article - from this DIY foundation - reveals the type of content, the genres, that are available for consideration by $\mathrm{PhD}$ students in particular. By commencing this process through the $\mathrm{PhD}$ candidature, an author profile and researcher profile can be developed, with a longevity, momentum and trajectory.

\section{Modelling and Managing Sonic Content: The Options}

Podcasts have many uses in teaching and learning. From their origins, undergraduate andragogy, learning design and assessment have dominated the literature. Their capacity for both knowledge generation and research dissemination has been under-researched, under-published and under-discussed. Using practice-led methods, this article offers ten genres of podcasts that can house, frame and enable research dissemination. A key caveat and comment must remain in place. Podcasts build relationships between teaching and research (Strickland, Gray, \& Hill, 2012, p. 1153-1161), such as learning-led research, teaching-led research and the Scholarship of Teaching and Learning (SoTL) (Harris \& Van Drie, 2015, p. 98-117). This mixed media research can be presented effectively through online journals with embedded sonic files, and distributed widely through open access. Therefore sounds can resonate sonically while nested in a scholarly discourse.

\subsection{Strategy One: When delivering a seminar, public lecture or presentation, produce a high quality recording before the event and upload it after the live presentation}

Conference presentations, seminars and keynotes have a finite, synchronous life. Certainly, the PowerPoint slides may travel. But PowerPoint is not a proxy for the resonance of public speaking. Sound matters. Also, the audiences - particularly at large conferences with multiple streams - are highly variable in size and interest. Massive intellectual effort is pumped into a scholarly presentation, only to have it witnessed by a handful of peers at a conference. This is particularly challenging for PhD students who may not be known beyond a finite circle in their lab and with few publications and citations. By time shifting an analogue presentation, it has a digital life beyond a particular time and room. The strength of recording sessions separately from a conference delivery is that the quality of the audio can be enhanced. The words can be delivered with attention to voice and pacing, rather than as derivative echo of a physical, gestural delivery. Then, if the presenter chooses, the questions can be recorded live and spliced to the pre-recording. 
For example, I delivered a keynote address at the University of Macau, exploring the new movements in doctoral education. I wanted to ensure that the speech itself was of high quality as it was the first lecture of its type on the PhD in the institution's history. I did not want the added worry of ensuring high quality sound for a digital asynchronous audience. Therefore, on the morning of the event, I recorded a sonic version in the hotel room. The resultant podcast was released as $4 \mathrm{D}$ : the revisioning of the $\mathrm{PhD}$, with an open access URL (http://traffic.libsyn.com/tarabrabazon/4D__the_revisioning_of_the_PhD.mp3). Therefore innovative ideas in research, and learning-led and teaching-led research, can find new audiences and reveal different dissemination strategies.

I have stressed - intentionally - these stand-alone and research-driven lectures, seminars and conference proceedings. Some of the earliest uses of podcasts involved recording undergraduate lectures to timeshift the content. The results of such a process are ambivalent at best and destructive to learning and student motivation at worst (Brabazon, 2002; Brabazon 2007; Brabazon, 2013). Luttenberger et al. confirmed that while lecture podcasts are "an efficient means for passing on learning content to students," a challenge emerges whereby a group completely disconnects from the content, not attending the lectures (because they are podcasted), but never listening to the podcasts (2018, p. 165-178). Therefore, the opportunity - through time shifting media - to not attend a lecture results in under motivated students not engaging with the learning materials on any platform. Fascinatingly Theodoros Karvounidis et al. similarly confirmed that student performance did not benefit through the use of 'new technologies,' but there were improvements in "the relative satisfaction of the participants" (2018: 935). In other words, technology was a proxy that assumed that learning was taking place. Twenty years of mediocre student management systems, bland templates and discussion fora have resulted in a perceptual confusion between learning and the interfaces of learning. Exposure to content is not learning, and in the case of undergraduates, the availability of podcasts does not confirm that they are heard. Instead, the satisfaction about their availability is high, because of convenience. For research-driven content and dissemination, the intrinsic motivation from already successful scholars is clear. Therefore this is an effective, efficient and evocative way of sharing research.

\subsection{Strategy Two: Microcontent through microinterviews}

Microinterviews are a strong genre that is ideally suited to podcasting. An expert, including colleagues or fellow doctoral candidates, can be asked a question. An answer can be recorded. These short sessions of two or three minutes work well in the definition of a concept or particular method or theory, or a key questions about a current event. Such a genre not only creates inventive, quirky and short content - delivered in two minutes - but this material also moves and plays with great effectiveness in lectures, tutorials, labs, seminars and learning management systems. It can also be referenced in publications as a sonic scaffold for the research. An idea can be trialled in a short sonic form and expanded into text-based research, while being able to reference the early exploration of these ideas. Through this strategy, high quality research can move into a diversity of locations at speed.

Examples of this genre, particularly focused on conceptual or definitional work, include "Post youth culture." I asked Steve Redhead to define the concept he created: http://traffic.libsyn.com/tarabrabazon/Post_youth_culture.mp3. It was then used to hook back into his research career by students and apply this theory in their own work. Another example, involved me 
asking Steve Redhead about 'speed' as a concept, activating Paul Virilio (http://traffic.libsyn.com/tarabrabazon/Speed_and_popular_culture.mp3). This very complex theoretical term was introduced - at speed - and with a gentle introduction, providing a gateway for reading about the topic. Therefore, these short sessions are an excellent way for $\mathrm{PhD}$ students and researchers to start podcasting, as they provide a short experiment with the software, and hardware and the output is able to be used and embedded in many forms.

\subsection{Strategy Three: Podcast the PhD candidature}

The Doctor of Philosophy is a long degree that can create an isolated and isolating experience for the student. Podcasting can provide a way to iteratively share the 'journey' of the doctorate, creating responsive and reflexive feedback for the candidate through social media. This innovative genre of podcast can either involve a supervisor and a student or an individual $\mathrm{PhD}$ scholar conducting a weekly or fortnightly podcast, discussing the progression of the work, personal challenges and reflection on the process. A loyal audience is attracted to the weekly episodes and they can - and do - offer feedback in real time, particularly when posted on Facebook, Twitter and LinkedIn.

There are examples of students who have done this. Anne McLeod, a student based in Dubbo, a regional hub in Australia, has podcasted throughout her thesis, from the first meeting through to doctoral submission. These podcasts have then been disseminated through Facebook, Twitter and LinkedIn. McLeod then receives feedback from friends and followers from around the world. Another fascinating, if unexpected and tragic use, was deployed by Mick Winter who also podcasted his doctoral journey. After completing his first full draft of his $\mathrm{PhD}$, Winter suddenly died. His supervisors, the author of this paper and Steve Redhead, then took this thesis and moved it through the drafting process. Yet examiners could - and did - listen to his candidature journey, captured through the podcasts and confirming research integrity, and then the supervisors presented the posthumous process for examiners in the thesis, ensuring transparency and accountability. The extract below is derived from the thesis.

\section{Supervisory Commentary}

Mr William 'Mick' Winter died on January 14, 2017. Professor Steve Redhead and Tara Brabazon the authors of this commentary - were his supervisors at both Charles Sturt University and Flinders University.

Before his death, Mick completed a full draft of the thesis and the document had passed through three editing cycles before his death. From this point, we have edited this final draft once more to confirm consistency, rigour and academic integrity. We present this draft for examination.

This is the version of the thesis that Mick presented, with one final edit from his supervisors. We confirm that this is his work - his research - and commend this scholarship to his examiners.

To verify research integrity for examiners, we also list the podcasts conducted with Mick Winter throughout his candidature. We also note podcast 38 , explaining to examiners how we prepared the script.

Mick Winter 1 - http://traffic.libsyn.com/tarabrabazon/Mick_Winter_1_-_memes_for_beginners.mp3 Mick Winter 2 - http://traffic.libsyn.com/tarabrabazon/Mick_Winter_2_- 


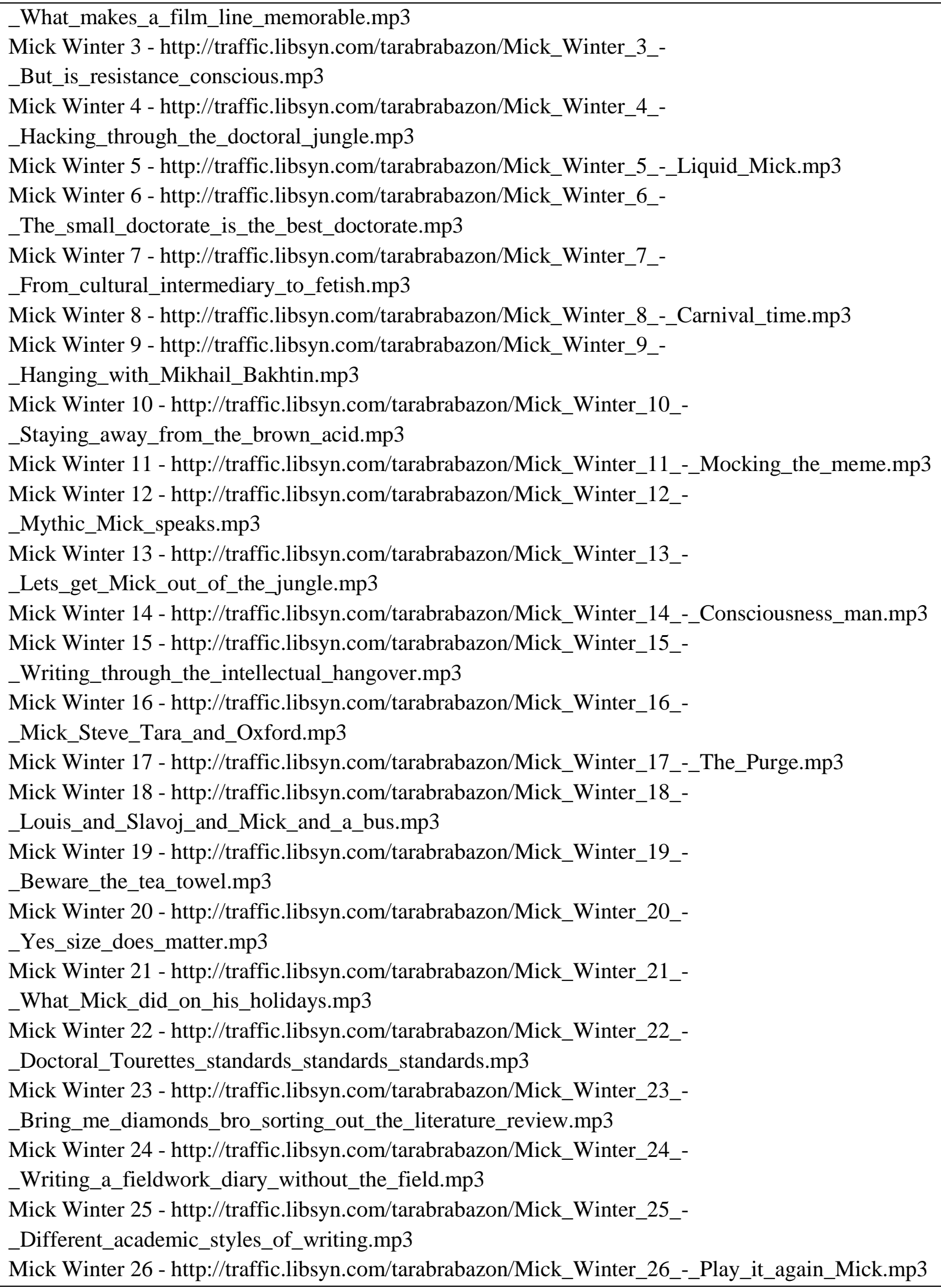




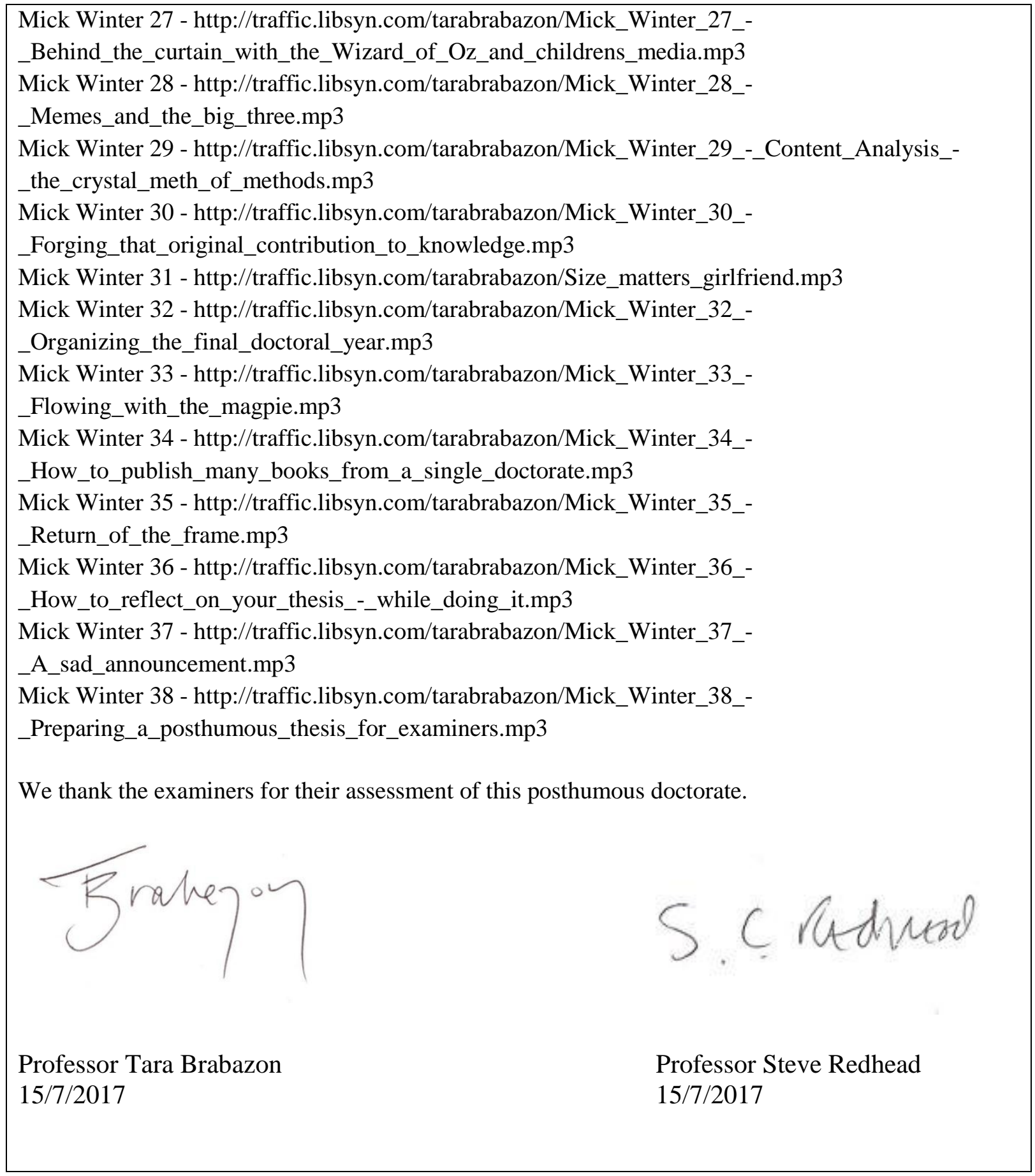

While posthumous theses are rare, the gift of the podcasted doctoral candidature ensured that the thesis progressed through examination with both research and professional integrity.

One further - and specialist - use of podcast was demonstrated by Mark Brown. Completing an artefact and exegesis thesis, podcasts were embedded into his method for artefact development and DIY 
modelling of the process. These podcasts were featured on his website and integrated with his wider technological experimentations (Brown, 2019). As his thesis investigated maker culture, the scaffolding of the podcasts in linking his artefact creations with the research was a key to his practice-led method.

\subsection{Strategy Four: Promoting research publications}

When an article, book chapter, book or professional publication is released, summoning an interested readership can be a challenge, particularly with the proliferation of digital platforms offering content of variable quality. One way to connect an audience with refereed research is via a podcast. This platform is ideal to convey the research narrative of the publication. New audiences and dissemination modes can be configured through the story-telling aspects of podcasting (Harter, 2019, p. 125-129). For a range of research areas, including health science and health studies, this mode of storytelling is enabling and translational. For example, Sue Charlton is a paediatric physiotherapist. After a distinguished professional career, she commenced a $\mathrm{PhD}$ exploring hip dysplasia and its differential diagnosis in regional and urban areas. The resultant podcast placed her doctorate and clustered publications into a context: (http://traffic.libsyn.com/tarabrabazon/Paediatric_physiotherapy_and_regional_health.mp3).

The integration between the research and podcast can be reinforced by linking to the piece in the information section. Such links translate research, and find new audiences, demonstrating and developing the key accountabilities in contemporary higher education: impact and engagement. Science communication is similarly an area of emerging research through podcasting (Dantas-Queiroz, Wentzel, Queiroz, 2018).

\subsection{Strategy Five: Podcasts from the field}

Conducting fieldwork can be an isolating and troubling time and space. Either extreme isolation or extreme engagement can emerge, resulting in aberrant behaviours and outcomes that may result in 'going rogue.' One strategy to maintain a connection with both the home base and the field, alongside a reflexivity about the research method, is to develop a podcast that reports on the fieldwork. Actual impressions can be captured in real-time and then they are available to cycles of interpretation and analysis. These podcasts can also be referenced in the doctoral thesis as a sonic diary of the process.

\subsection{Strategy Six: Capture and disseminate high theory and abstract ideas}

Sound-only media are ideal to work through intricate concepts and theories. Because the concentration is on sound, without the visual distraction, high level theoretical conversations are effectively configured through podcasts. The Open University, pre-digitization, used sound in this way to teach and share the abstract, complex and difficult. The Open University were innovators in media education and the reasons for the success were realized by Gary Berg who stressed three nodes of innovation: high quality content, student support and a strong research base (Berg, 2001, p. 5-6). This powerful nexus, which has been displaced through the university sector purchasing learning management systems that relinquished so many of the reflexive stages of learning design, meant that the selection of media was always configured to support learning goals. The OU were international innovators in the development of a proto-digital sonic literacy. A.W. Bates, in reviewing the successes of the Open University, showed the 
importance of media choice and selection in distance education, including the history of audio cassettes for OU courses. He stated that, "Audio cassettes are low costs; all students already have facilities at home; they are easy for academics to produce, and cheap and simple to distribute; students find them convenient to use; and, when designed properly, they encourage student activity. (UK OU audiocassettes are rarely lectures)" (Bates, 1993, p. 242). This review of the analogue environment has relevance when ascertaining the applicability of digital platform choices. The Open University chose audio cassettes because they were low cost, accessible, able to be produced by academics without intervention from technicians, and convenient to use. In terms of educational design, lectures were noted as inappropriate in developing effective sound-based OU educational strategies. The key realization then and now - is that the media selected for curriculum delivery must be determined by the student's home environment. Audio cassettes were cheap. Broadband, iPhones and computers are not. However the foundation created by the Open University, which they continue with podcasts, is to ensure that sound-only delivery is valued on its own terms, rather than as a less effective platform than video. With the eyes at rest new patterns for thought and interpretation emerge.

\subsection{Strategy Seven: Talk through an argument before it is written}

Complex research emerges through many pathways. Developing research questions, gathering data sets, engaging in complex methodological and theoretical conversations is both challenging and productive. Gaining incremental feedback through the initial stages of this process is particularly valuable and important. Podcasting is a key path through this process of establishing the viability of an inter/anti/postdisciplinary research project. I watched this model operate in real time. My late husband, Professor Steve Redhead, recorded 12 podcasts around the theme of 'Theoretical Times.' We used podcasts to test the viability of an argument that problematized the foundational viability of disciplinary knowledge. We recorded one podcast a day over the Christmas break of 2015-2016. I edited and uploaded these sessions on the day of their recording and posted links throughout social media. Feedback arrived from colleagues around the world from Facebook, LinkedIn and Twitter. From these podcasts and responsive commentary, he realized that the project was viable and would find an audience of readers. Upon this confirmation, he was able to write the book, using the podcast as the spine for the chapters. He then expanded on the podcasted arguments and feedback on his website via a regular blog series. These podcasts and blogs branded the title Theoretical Times and one of the reasons that the presales and sales of the monograph were so high is through the foundation created through the podcasts. Yet the blogs and the book began with podcasts, testing arguments through sound.

The credibility of such scholarly podcasts is changing. In 2019, the University of Sussex research repository, Sussex Research Online, incorporated audio 'item types' into the database. Martin Spinelli uploaded "For your ears only" (Spinelli, 2019), an eight-part audio series exploring the literary capacity of podcasting. Using an interview mode to explore the capacities of podcasting, what makes this case unusual is that the sonic artefact was accepted into a research repository. Therefore, this platform and mode for expressing complex intellectual ideas through sound is gaining not only popularity and currency, but institutional credibility. 


\subsection{Strategy Eight: Interviews with interesting people and leaders in a field}

One characteristic of academic life is mobility. As we travel around the world for fieldwork, conferences, seminars and keynotes, we meet leaders in our research fields. Therefore, scholars have an opportunity to interview these scholars and disseminate that conversation. These senior scholars will then lift the profile of not only the interviewer but the entire podcast series, resulting in an increased profile for the work. Such a profile matters to doctoral students in a cluttered digital environment, struggling to build their research career and trajectory. However it is also opportune to share high quality content via open access to new audiences.

As public funding for education reduces, alongside support for conferences and travel, it is important to add value to all opportunities. For example, I was delivering a keynote presentation at the Institute of Education in London. I took the opportunity to visit Manchester, conducted fieldwork and archival research in a two day visit and interviewed Dr Kevin Moore, then head of the National Football Museum. I had conducted research on the National Football Museum while it was resident in Preston. As part of my GLAMs (Galleries, Libraries, Archives and Museums) research, I took the opportunity to speak with Dr Moore about the movement from Preston to Manchester and the benefits and challenges of this shift. The resultant podcast (http://traffic.libsyn.com/tarabrabazon/A_conversation_with_Kevin_Moore_Museums_and_Popular_C ulture_Revisited.mp3) - profiled his important book, but also demonstrated and disseminated the relationship between knowledge-generating institutions, particularly museums and universities.

\subsection{Strategy Nine: Record a seminar on a key new article or book with your friends, colleagues and fellow PhD students}

Occasionally, a major and influential book or article emerges. When this occurs, it is timely and appropriate to gather the members of the laboratory or colleagues in a research section or community, read the piece and record the discussion or seminar. This process disseminates high quality and interactive content to the world and enables a discussion about new ideas. The community-building components of podcasting remain important and an increasing trajectory of the research (Kuklo, 2018). For example, when Guy Standing released his new book, The Corruption of Capitalism, Flinders University $\mathrm{PhD}$ students gathered to discuss this research. Students outside of Adelaide joined via Skype, and the discussion offered an infusion of new ideas for students and a demonstration of the value of disciplines aligning to explore major social and intellectual movements. This conversation was recorded, edited and released as part of the Office of Graduate Research podcast series (http://traffic.libsyn.com/tarabrabazon/Guy_Standings_The_Corruption_of_Capitalism_A_Flinders_rea ding_group.mp3). $\mathrm{PhD}$ students gain experience in reading and disseminating their views for an audience.

\subsection{Strategy Ten: Configure your content for new audiences}

At its best, podcasts have a translation function. Whatever the profession, but particularly health and education, the research that is published in the refereed literature has a series of other allied audiences. Some work is required to make those connections and translate the research for diverse communities that 
may use the results, outcomes of innovations. Podcasts are powerful and direct in enabling this translational work. They can construct and occupy a different space that refers back to an article and results, and presents the research narrative about why the research matters to this group of professionals. Podcasts create a connection - and builds communication bridges and scaffolds. Allied Health remains a great source for this translational work. For example, Monica Lawrence is researching cardiac health in remote indigenous communities. Her refereed research is important. But the impact of her results and processes deserves a much wider audience. A podcast enabled that proliferation of her readership: http://traffic.libsyn.com/tarabrabazon/Remote_health_-_indigenous_knowledge.mp3.

\section{Why Podcasting Matters}

The previous section presented ten genres or modes of content that can be created by $\mathrm{PhD}$ students, using the distinctive capacities of podcasts. This content can be created today, this week, this month and this year. But the major question remains, why step into podcasting, particularly as a doctoral candidate or early career researcher? I describe social media - particularly for academics - as a funnel. The material we create - monographs, book chapters, refereed articles, professional publications, conference proceedings, videos or podcasts - all pass through this funnel. Content is created for a wide group, but in specific ways. This is not broadcasting. This is narrowcasting. We as scholars wish to disseminate research. Yet too often, scholars hope that their work will be found, read and cited. Research is treated like a dart and our readership or audience is a dart board. In a time of information glut, clear dissemination strategies are required. Attention to multimodality and the relationship between content, platform and audience, ensure the subtle construction of interfaces for research dissemination. As Richardson and Green confirmed in the context of their research on modernism:

Interrogating the function of spoken voices within our scholarship, it is further interesting to consider how the podcast form allows practitioners to platform the voices of female modernists alongside female scholars. Whereas monographs, journals and other traditional textual scholarship employ the quotation, the podcast is able to utilize the sound bite, embedding clips from original radio broadcasts, television interviews and related media ... In the process of transcription, something is lost. Texture, intonation, accent are all important to the broadcast experience (2018, p. 286).

To continue with the funnel metaphor, at the top of the funnel is free content that is delivered at speed and is available to everyone with an internet connection. Free, high quality content that can slot into the lives of a readership is incredibly valuable. Podcasts are the ideal example of this effective interface. Podcasts can accompany a commute (Bijsterveld, Cleophas, Krebs and Mom, 2014), a walk, exercise or 'dead' spaces of waiting for people, deliveries or an appointment. Podcasts create intimacy, a connection. Emotion in academic life is an under-researched field (Askins, 2009, p. 4-13). But that emotional connectivity with readers not only summons social and political change, but may also feed into premium content.

I have a very wide content funnel. The overwhelming majority of my content - my academic content is free: podcasts, videos, open access journal articles and open access journalism. Over $90 \%$ of my academic material is open access. This free material, multimodally designed to access broad audiences, 
then funnels into books. I select publishers that go for the diversity of books including hard back, paperback, ebook and - for the first time - audiobook for Trump Studies (Brabazon, Redhead, \& Chivaura, 2018). Most of my scholarship is freely available. The punk, DIY material is created through social media or linked through it. The books are monetized. The books are bought. The remaining content is free.

The book publishing industry is also transforming. For the first two decades of my career, only strong academic monographs were published, many by university presses. But I am now also publishing more trade-oriented academic books as well. Still the funnel will be wide. Yet audiences - readerships - find me through the free and open access material, through text, sound and vision. That content can then scaffold into the immersive experience of a book, which is purchased. Therefore, it is in the interests of academics to consider their social media funnel. For each individual academic, what is the premium content? That premium content may not emerge today, but through the next five, ten or twenty years. Further consideration is of the material that creates an allegiance or an authentic relationship with a readership, but also the credibility granted to the resultant research (Supper, 2012). That configuration is often described as an author platform. While so much attention is placed on journal rankings and citation rates, through social media and open access publications, knowledge is sliced and shared in different ways. Individuals are followed in social media. By linking to a specific research object, the journal itself melts away to enable an engagement with a single article, podcast or digital object. Podcasts remain important to this conversation. R. Michael Winters et al. asked a key question: "How can the data and images of social media posts be transformed into something as meaningful and vivid in the auditory sense?"(Winters, Joshi, Cutrell, \& Morris, 2018) This article has added a layer and texture onto Winters' inquiry, exploring how auditory objects - sonic social media - can be rendered meaningful in a scholarly sense.

Sound-based media builds relationships with a readership, building and enhancing a researcher's platform from which to speak. But podcasts are distinctive: they are intelligent, evocative and passionate, a hot and engaging medium in a time of digital saturation. They fulfil a punk role in academic life, transcending legacy media, by whispering in the ear of a scholar or stakeholder. Lynn Harter captured the change and its importance for research and researchers in this confused time:

Scholars read and write. Citation chains compose bodies of research, linking authors and advancing theory. This is my home. I love the written word ... That said, conventional research reports are limited in their ability to register the visceral experience of suffering and resilience (2019, p. 126).

In a time where 'fake news' is summoned to mask mediocre thinking, occupying academic communications processes in new ways and through new genres of dissemination is meaningful, hopeful and necessary. Scholars matter. Scholarship matters more. Podcasts offer a way to embody a scholar's research while arching it beyond the university. Research dissemination is a simply phrase to use, and a complex process to enact. Yet sound - unlike vision - bends around corners. We cannot see around a corner, but we can hear and be heard beyond our vision. If we are to engage with our intellectual future, then we must learn to think, read, hear and interpret beyond the road we see in front of us. 


\section{References}

Askins, K. (2009). That's just what I do: Placing emotion in academic activism. Emotion, Space and Society, 2(1), 4-13

Baker, C. (2019). New directions in mobile media and performance. Abingdon: Routledge,

Bates, A. (1993). Technology for distance education: A 10-year perspective, in Tait, A., ed. Key issues in open learning - a reader: An anthology from the journal 'Open learning' 1986-1992, Harlow: Longman.

Berg, G. (2001). The British Invasion. WebNet Journal, January-March, 5-6.

Bijsterveld, K., Cleophas, E., Krebs, S., \& Mom, G. (2014). Sound and Safe: A history of listening behind the wheel. Oxford: Oxford University Press.

Brabazon, T. (2013). Digital Dieting. Aldershot: Ashgate.

Brabazon, T. (2002). Digital Hemlock, Sydney: UNSW Press.

Brabazon, T. (2018). It is with well-deep sadness. Twitter, March 8. https://twitter.com/tarabrabazon/status/971397247211487233?lang=en

Brabazon, T. (2007). The University of Google. Aldershot: Ashgate.

Brabazon, T., Redhead, S., \& Chivaura, R. (2018). Trump Studies: An intellectual guide to why citizens vote against their own interests. Bingley: Emerald.

Brabazon, T., Redhead, S., (2018). Chivaura, R. Trump Studies audio book. https://www.amazon.com.au/Trump-Studies-Intellectual-CitizensInterests/dp/B07K6Z7FDN/ref=sr_1_1?keywords=Trump+Studies\&qid=1554363057\&s=gate way\&sr $=8-1$

Brabazon, T., \& Grand, P. (2018). New publishing. New voices. Office of Graduate Research YouTube Channel. Retrieved on June 28 from https://www.youtube.com/watch?v=k0wZX4lplP8\&t=5s

Brabazon, T., \& Redhead, S. (2016). University of Trumpland. Libsyn, Retrieved on November 13 from http://traffic.libsyn.com/tarabrabazon/University_of_Trumpland.mp3

Brown, M. (2019). Tracing the path podcast, http://www.mark-brown.com.au/page0/

Campbell, G. (2005). There's something in the air: Podcasting in education. EDUCAUSE Review, 40(6), 32-47.

Coles, T. (2014). Never mind the inspectors, here's punk learning. Carmarthen: Independent Thinking Press.

Dantas-Queiroz, M., Wentzel, L., \& Queiroz, L. (2018). Science communication podcasting in Brazil: The potential and challenges depicted by two podcasts. An. Acad. Bras. Science, 90(2).

Dasal, J. (2018). Podcast perfection: The right questions and tools for starting a winning audio show.

Darko, N. (2018). 3,2, 1 Podcast, (Purposely created publishing group).

Eiman, M. (2017). Podcast: Learn how to stop babbling and start podcasting like a pro.

Foley, K. (2018). Case study 22: The PodMag: Podcasting to promote academic community, in R. Matheson, S. Tagney and M. Sutcliffe (eds), Transition In, Through and Out of Higher Education: International Case Studies and Best Practice. Routledge (pp. 154-156).

Goodall, G. (2011). Sonic persuasion: Reading sound in the recorded age. Urbana: University of Illinois Press.

Goodall, H. (2010). Counter-narrative: How progressive academics can challenge extremists and promote social justice. Walnut Creek: Left Coast Press.

Harris, A., Van Drie, M. (2015). Sharing sound: Teaching, learning and researching sonic skills. Sound Studies: An interdisciplinary journal, 1(1), 98-117.

Harter, L. (2019). Storytelling in acoustic spaces: Podcasting as embodied and engaged scholarship. Health Communication, 34(1), 125-129.

Kane, B. (2015). Sound Studies without auditory culture: A critique of the ontological turn. Sound Studies: An interdisciplinary Journal, 1(10), 2-21. 
Karvounidis, T., Chimos, K., Bersimis, S., \& Douligeris, C. (2018). Factors, issues and interdependencies in the incorporation of a Web 2.0 based learning environment in higher education. Educ Inf Technol, 23.

Katz, M. (2018). Podcast listeners really are the holy grail advertisers hoped they would be. Wired, Retrieved on January 29 from https://www.wired.com/story/apple-podcast-analytics-firstmonth/

Kim, Y., Morton, B., Gregorio, J., Rosen, D., Edouard, K., \& Vallett, R. (2019). Enabling creative collaboration for all levels of learning. PNAS, 116(6).

Knight, A. (2019). Theserialeavesdropper has logged on: towards an aural equivalent of the gaze. Brow Books. Retrieved on March 18 from https://www.theliftedbrow.com/liftedbrow/2019/3/15/excerpt-theserialeavesdropper-haslogged-on-toward-an-aural-equivalent-of-the-gaze-by-aimee-knight-41

Kuklo, P. (2018). The future of podcasting: envisioning an audio stories community for listeners and creators, where they connect through similar interests and share inspiring content. Masters in Interactional Design. Faculty of Science and Technology, Umea University.

Laurin, A. (2018). The book on podcasting: Podcasts for personal and professional development. Whitby: Alexander Laurin.

Luttenberger, S., Macher, D., Maidl, V., Rominger, C., Aydin, N., \& Paechter, M. (2018). Different patterns of university students' integration of lecture podcasts, learning materials, and lecture attendance in a psychology course. Education Inf Technol, 23, 165-178.

Maalsen, S. (2019). The social life of sound. Singapore: Palgrave.

Quah, N. (2018). Apple's new analytics for podcasts. Niemanlab. Retrieved from http://www.niemanlab.org/2017/06/apples-new-analytics-for-podcasts-mean-a-lot-of-changesome-good-some-inconvenient-is-on-the-way/

Richardson, S., \& Green, H. (2018). Talking women / women talking: the feminist potential of podcasting for modernist studies. Feminist Modernist Studies, 1(3).

Sanford, J. (2002). Community invited to read Great Expectations in serial format. Stanford Report, Retrieved on October 16 from https://news.stanford.edu/news/2002/october16/dickens1016.html

Spinelli, M. (2019). For your ears only. Sussex Research Online. http://sro.sussex.ac.uk/id/eprint/75916

Strickland, K., Gray, C., \& Hill, G. (2012). The use of podcasts to enhance research-teaching linkages in undergraduate nursing students. Nurse Education in Practice, 12(4), 1153-1161.

Supper, A. (2012). Lobbying for the ear: The public fascination with and academic legitimacy of the sonification of scientific data. PhD Thesis, Universitaire Pers Maastricht, Maastricht, Netherlands.

Tiffe, R., \& Hoffman, M. (2017). Taking up sonic space: Feminized vocality and podcasting as resistance. Feminist Media Studies, 17(1), 115-118.

Winters, R., Joshi, N., Cutrell, E., Morris, M. (2018). Strategies for auditory display of social media. Ergonomics in Design. Retrieved on November 2 from http://doi.org/10.1177/1064804618788098 